\title{
What Impacts Skin Color in Digital Photos?
}

\author{
Albrecht Lindner and Stefan Winkler
}

$\overline{\bar{\pi}}$ University of Illinois

I at Urbana-Champaign
ADSC

Advanced Digital Sciences Center 


\title{
Outline
}

\author{
I. Statistical Framework: \\ Image-Mining \\ 2. Impact on Skin Color \\ 3. Skin Detection
}


Statistical Framework 


\section{Statistical Framework}

Claudia Schiffer
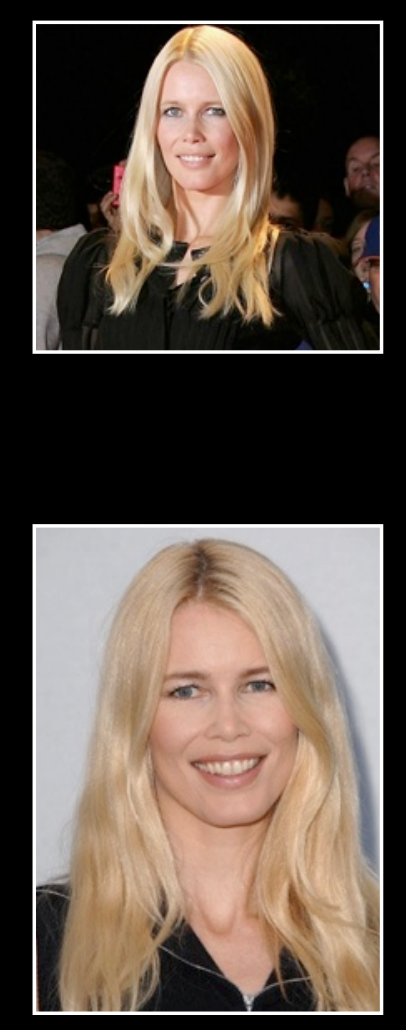

Will Smith
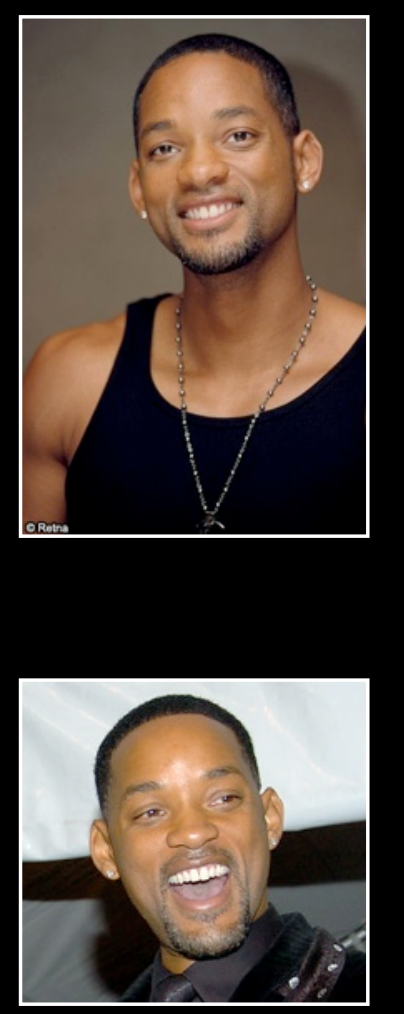
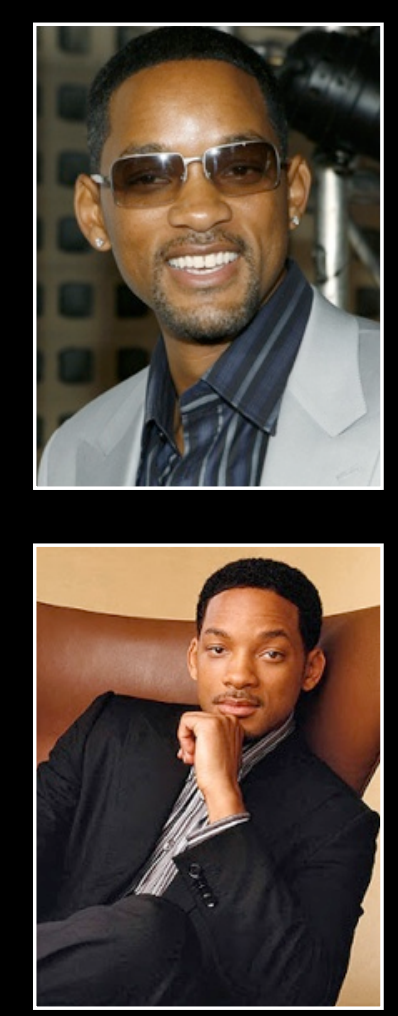

George Clooney
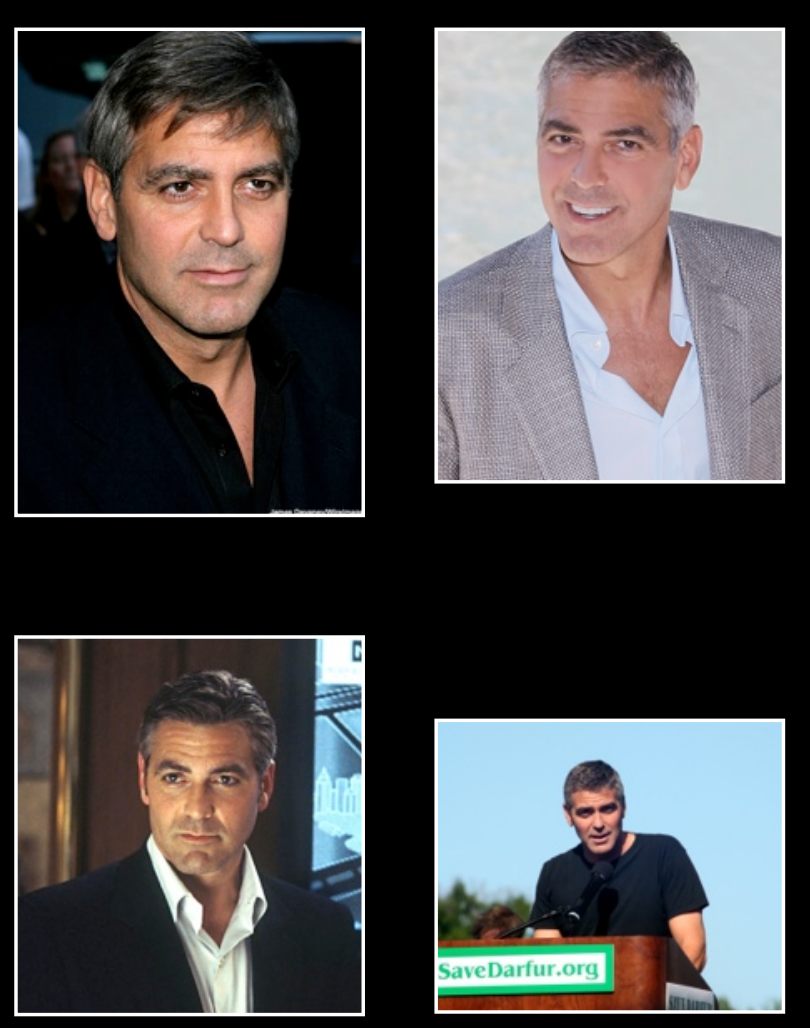


\section{Statistical Framework}

Claudia Schiffer

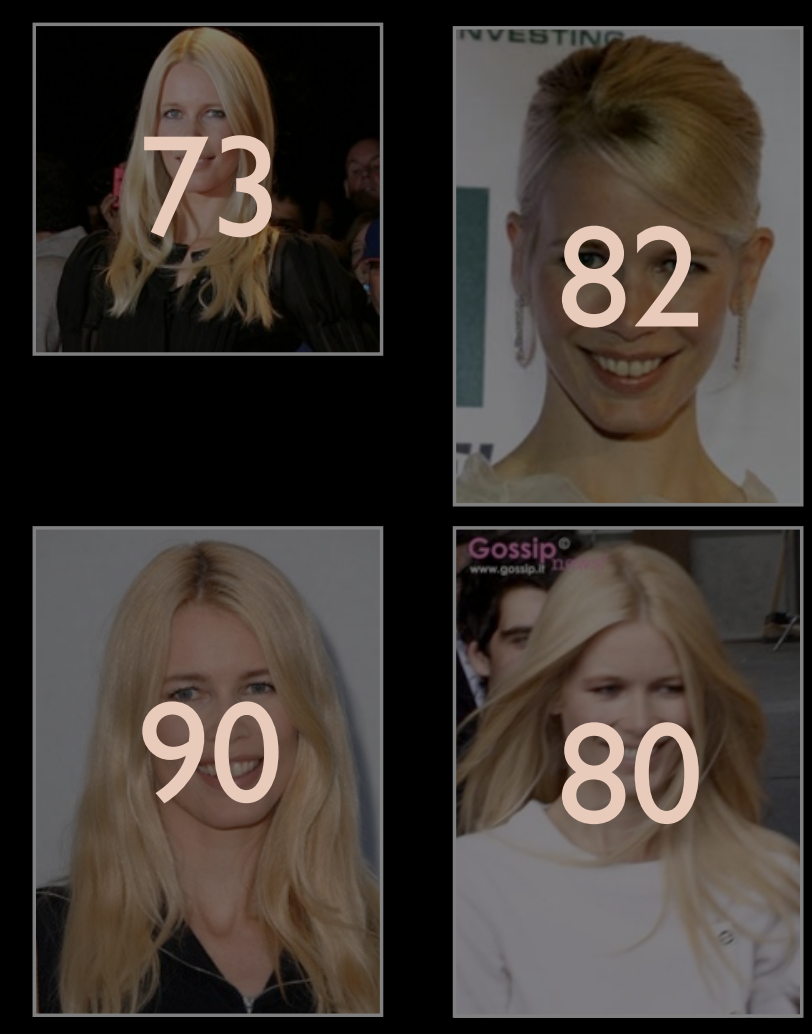

Will Smith
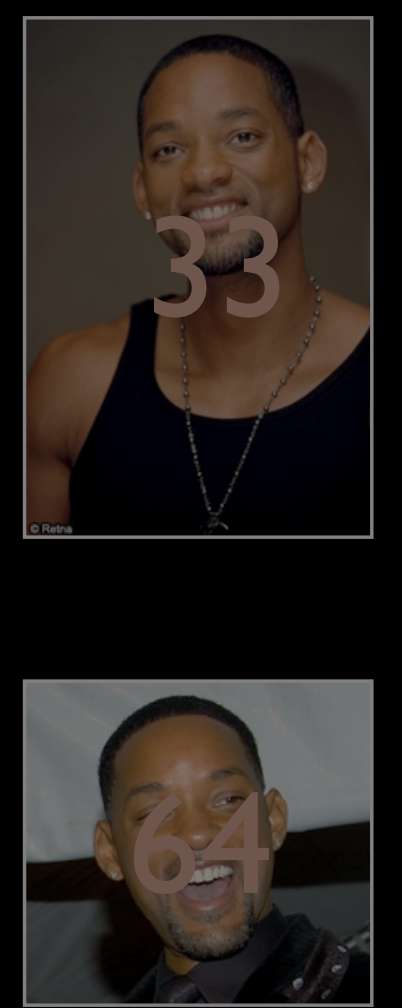
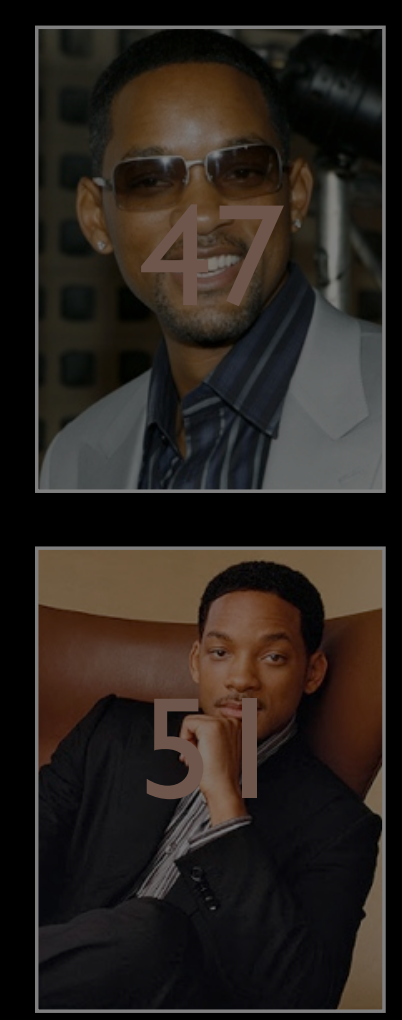

George Clooney
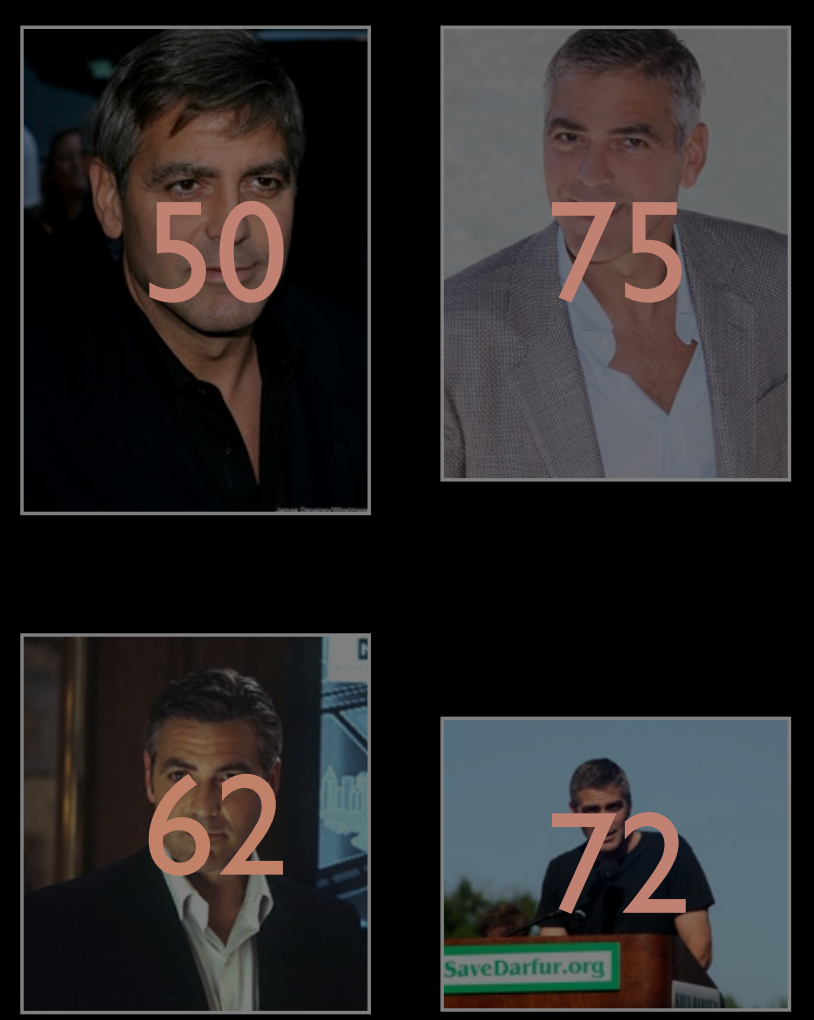

$\%$ bright-ish skin tone pixels 


\section{Statistical Framework}

sorted list $33 \begin{array}{llllllllllll}3 & 47 & 50 & 5 \mid & 62 & 64 & 72 & 73 & 75 & 80 & 82 & 90\end{array}$

rank index $\quad \mid \begin{array}{lllllllllllll} & 2 & 3 & 4 & 5 & 6 & 7 & 8 & 9 & 10 & \text { II } & 12\end{array}$

ranksum $T=\mid+2+4+6=13$ 


\section{Statistical Framework}

sorted list 33 \begin{tabular}{llll|llllllll}
3 & 47 & 50 & $5 \mid$ & 62 & 64 & 72 & 73 & 75 & 80 & 82 & 90
\end{tabular}

$\begin{array}{llllllllllllll}\text { rank index } & \mid & 2 & 3 & 4 & 5 & 6 & 7 & 8 & 9 & 10 & \text { II } & \text { I2 }\end{array}$

ranksum $T=\mid+2+4+6=13$

Mann-Whitney-Wilcoxon ranksum test

$$
\mu_{T}=\frac{n_{1}\left(n_{1}+n_{2}+1\right)}{2} \quad \sigma_{T}^{2}=\frac{n_{1} n_{2}\left(n_{1}+n_{2}+1\right)}{12}
$$

$n_{1}=4$ cardinalities

$n_{2}=8$ of both sets

$$
z=\frac{T-\mu_{T}}{\sigma_{T}}=\frac{13-26}{5.88} \approx-2.21
$$

[F. Wilcoxon, Individual comparisons by ranking methods, Biometrics Bulletin, I (6):80-83, I945] 


\section{Statistical Framework}

sorted list $333 \quad 47 \quad 50 \quad 5 \mid \begin{array}{lllllllll}62 & 64 & 72 & 73 & 75 & 80 & 82 & 90\end{array}$

$\begin{array}{llllllllllllll}\text { rank index } & \mid & 2 & 3 & 4 & 5 & 6 & 7 & 8 & 9 & 10 & \text { II } & \text { I2 }\end{array}$

ranksum $T=1+2+4+6=13$

Mann-Whitney-Wilcoxon ranksum test

$$
\mu_{T}=\frac{n_{1}\left(n_{1}+n_{2}+1\right)}{2} \quad \sigma_{T}^{2}=\frac{n_{1} n_{2}\left(n_{1}+n_{2}+1\right)}{12}
$$

$n_{1}=4$ cardinalities

$n_{2}=8$ of both sets

$$
z=\frac{T-\mu_{T}}{\sigma_{T}}=\frac{13-26}{5.88} \approx-2.21
$$

$z<0 \rightarrow$ Will Smith has few bright skin tone pixels. 


\section{Statistical Framework}

sorted list $33 \begin{array}{llllllllllll}3 & 47 & 50 & 5 \mid & 62 & 64 & 72 & 73 & 75 & 80 & 82 & 90\end{array}$

$\begin{array}{llllllllllllll}\text { rank index } & \mid & 2 & 3 & 4 & 5 & 6 & 7 & 8 & 9 & 10 & \text { II } & \text { I2 }\end{array}$

ranksum $T=1+2+4+6=13$

$$
T=8+|0+||+| 2=4 \mid
$$

Mann-Whitney-Wilcoxon ranksum test

$$
\text { Will Smith } z=\frac{T-\mu_{T}}{\sigma_{T}}=\frac{13-26}{5.88} \approx-2.21
$$

Claudia Schiffer $z=\frac{T-\mu_{T}}{\sigma_{T}}=\frac{41-26}{5.88} \approx 2.55$ 


\section{Skin color distribution}

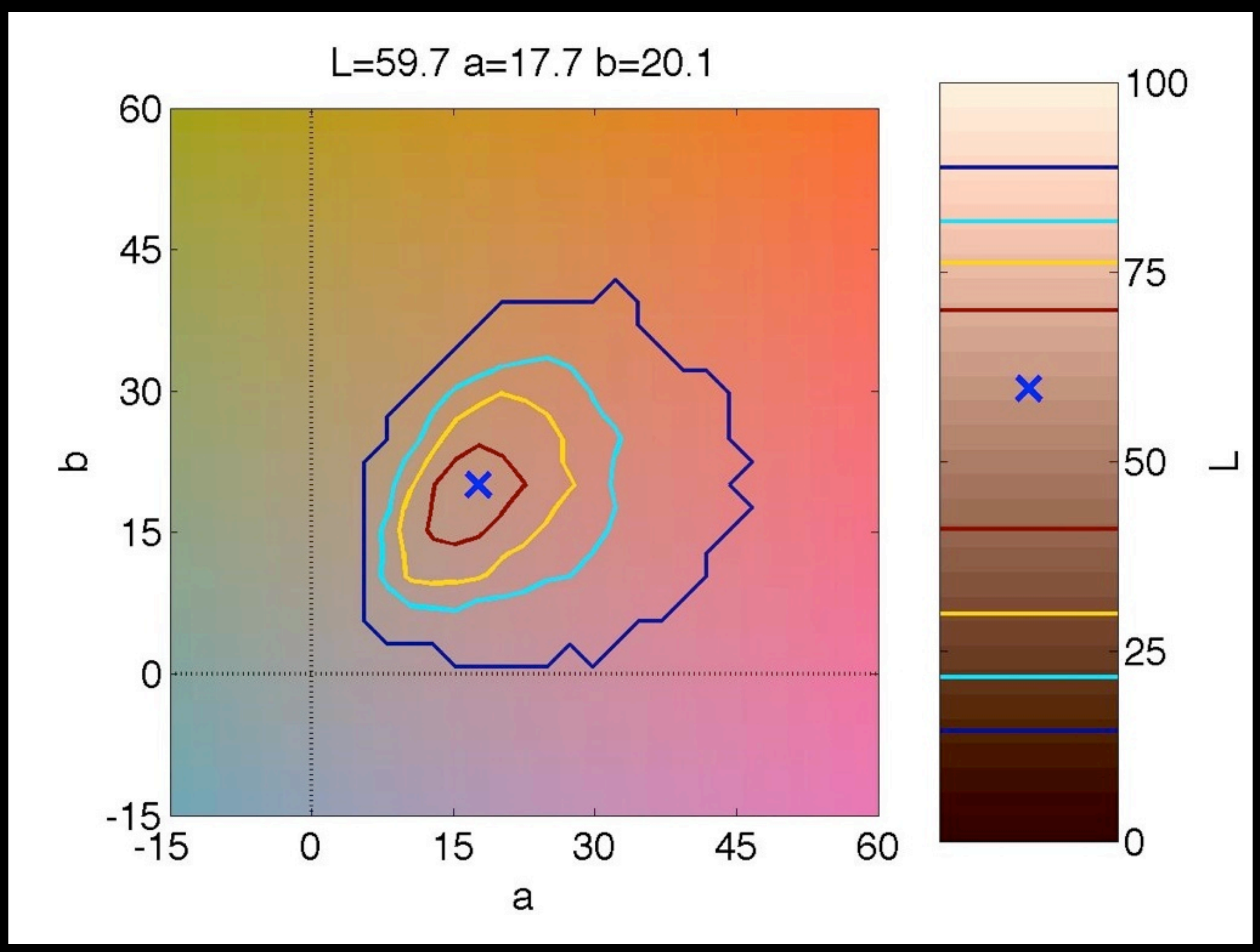




\section{Impact of Metadata}




\section{Databases}
- Geolocation: 6 × 12 grid cells on the globe, 68,795 images
- Cameratype: mainly Canon and Nikon, 25,585 images
- Flash: On or Off, 22,387 images
$\frac{\Phi}{a 0} \mid \bullet$ Keyword: sunburn, 美女, and 45 other keywords, نे 8,585 images
- PubFig: I40 different persons, 24,7| 3 images 


\section{Geolocation}

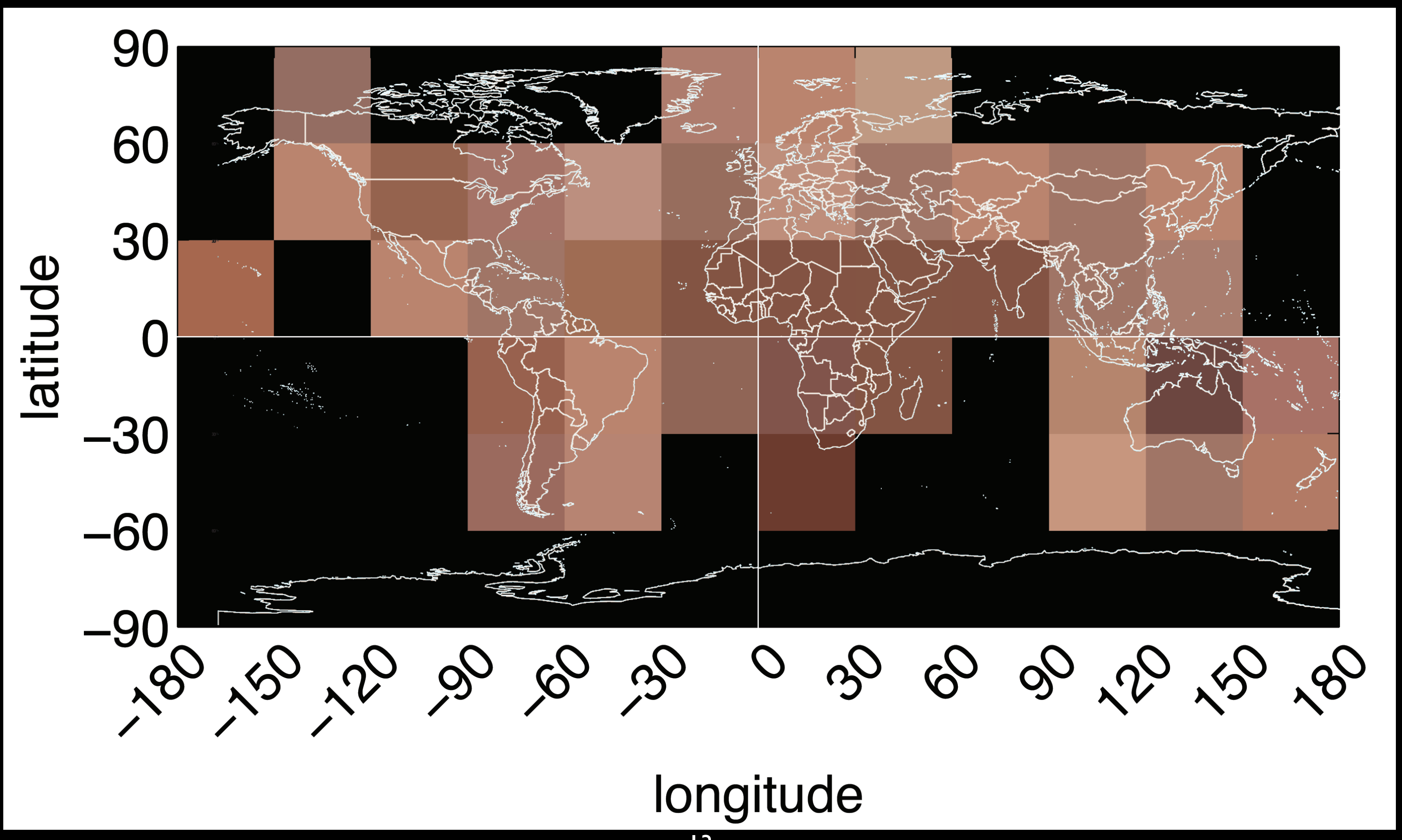




\section{Geolocation}

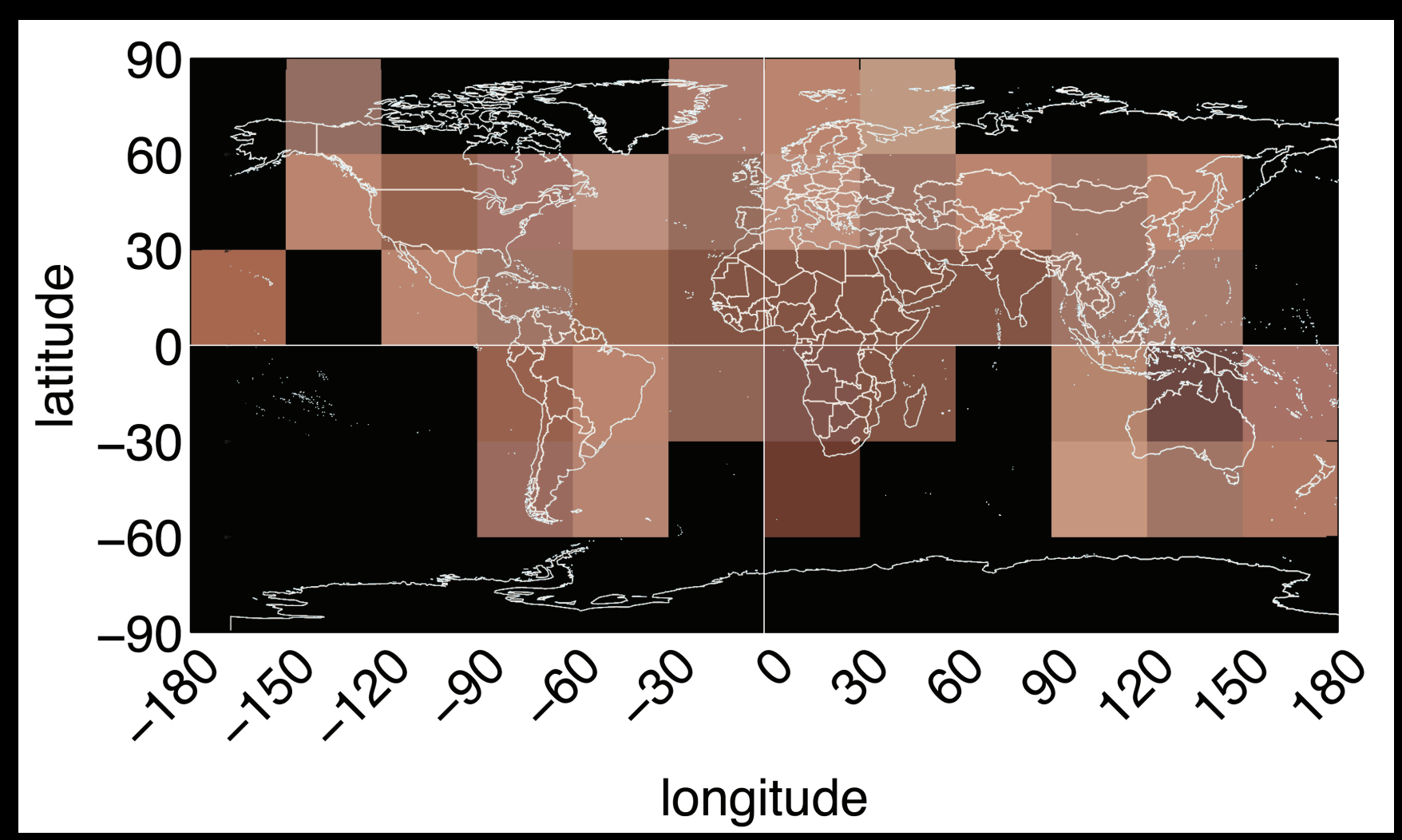

- Geolocation impacts skin colors.

- Photographer's origin might be just as important. 


\section{PubFig}

Barack Obama

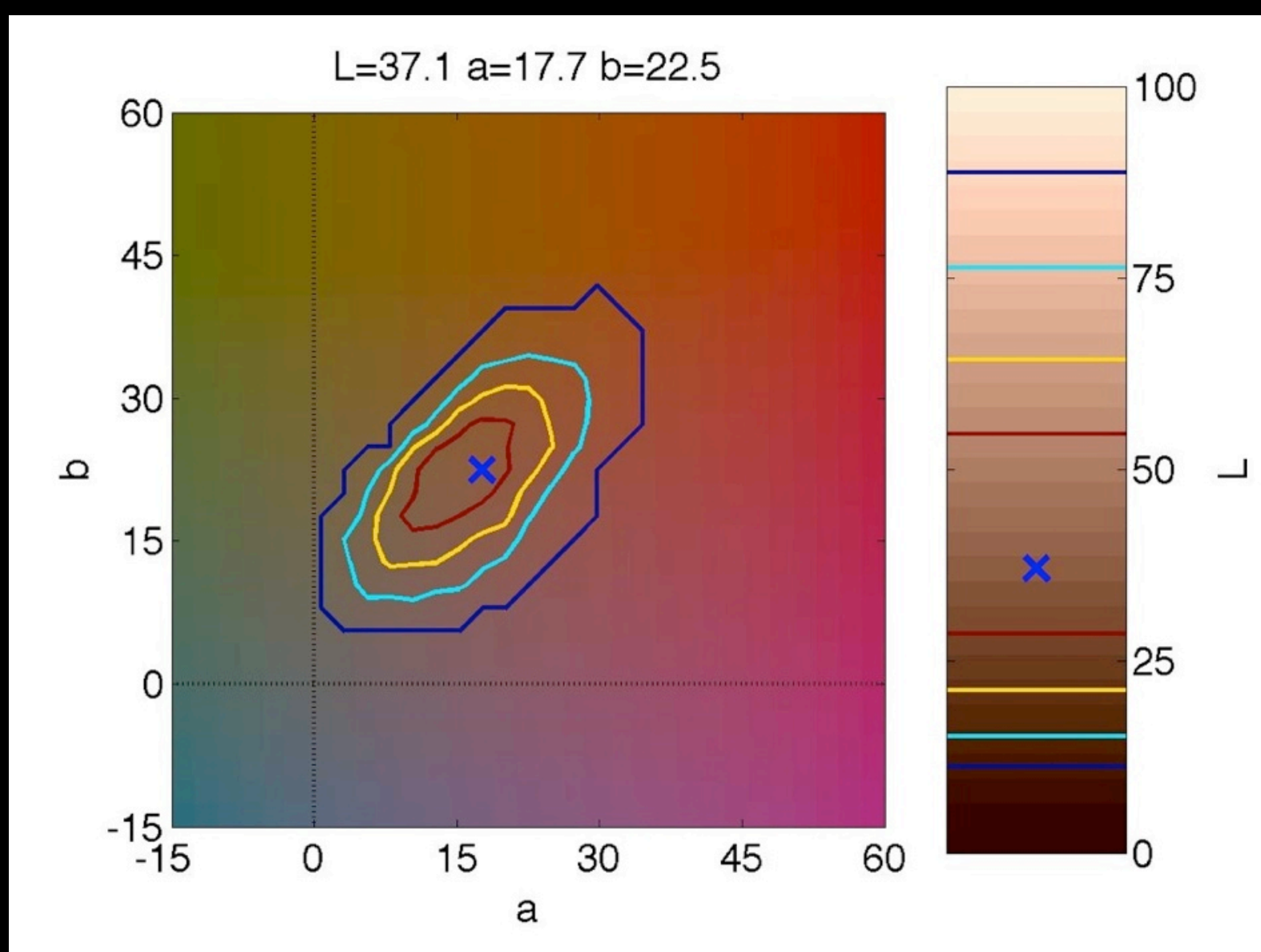

Claudia Schiffer

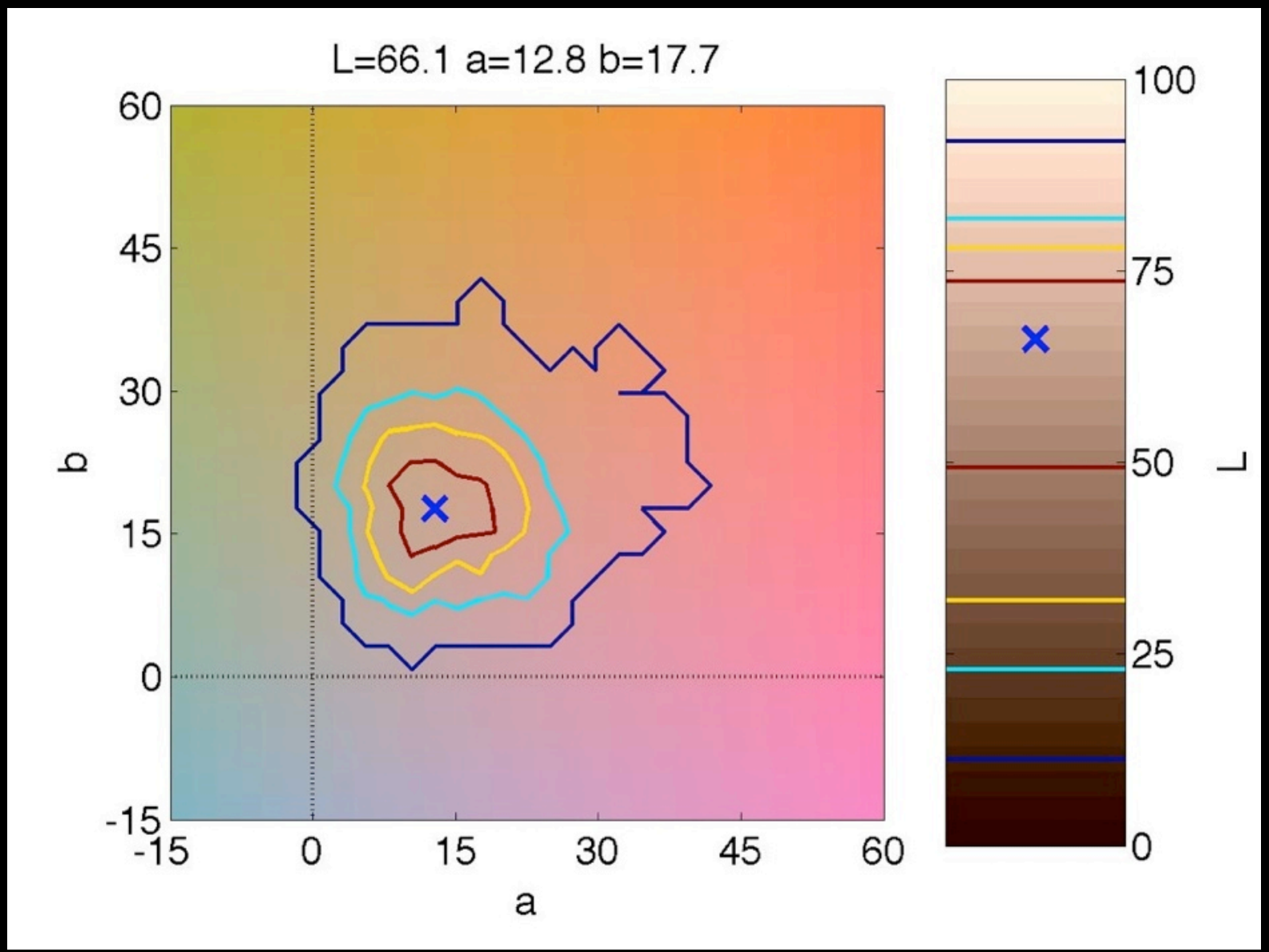

Barack Obama has a darker more saturated distribution than Claudia Schiffer. 


\section{Keywords}

\section{geisha}

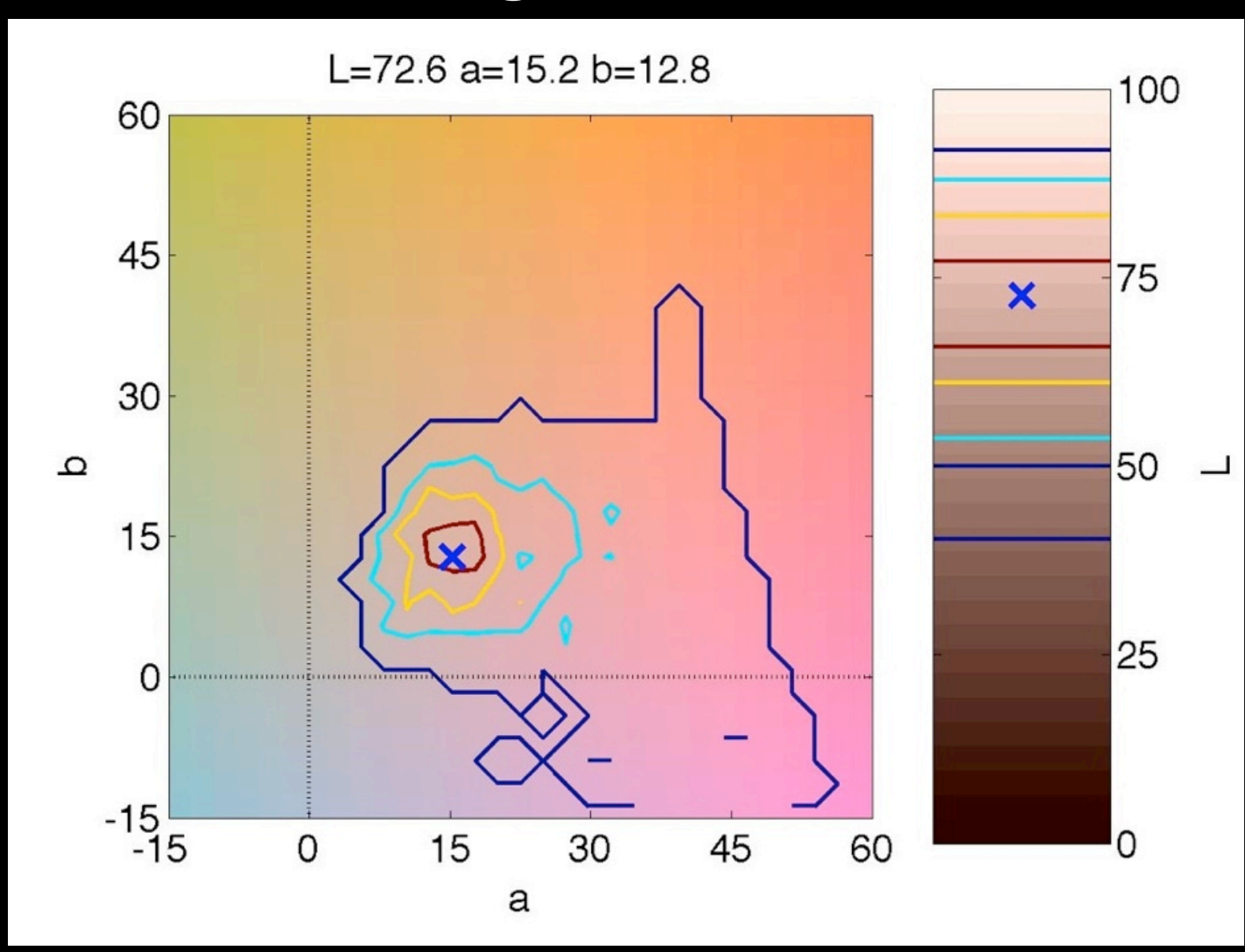

\section{dark skinned}

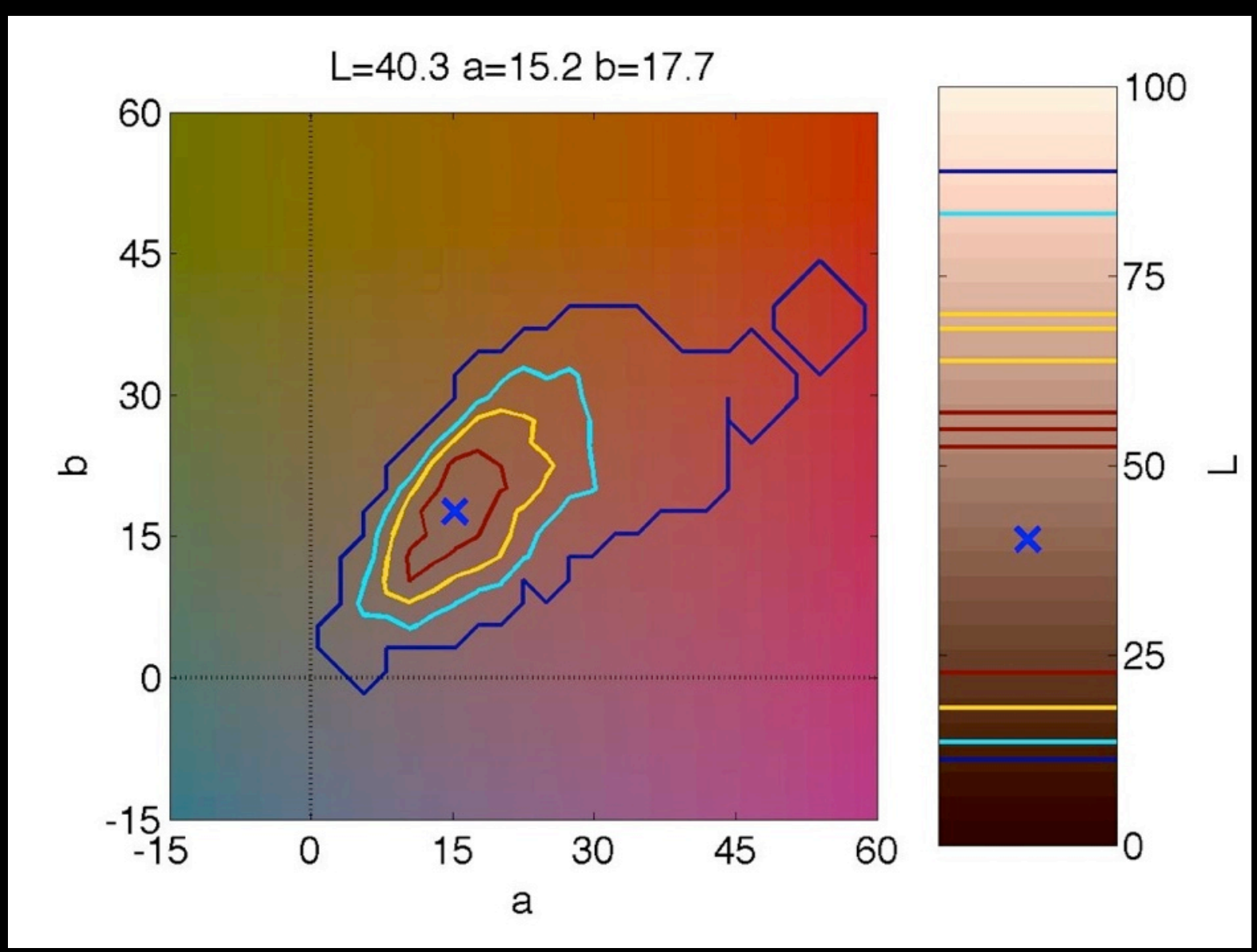

Geisha:Japanese women with very pale (almost white) make-up. 


\section{Cameratype}

\section{Canon}

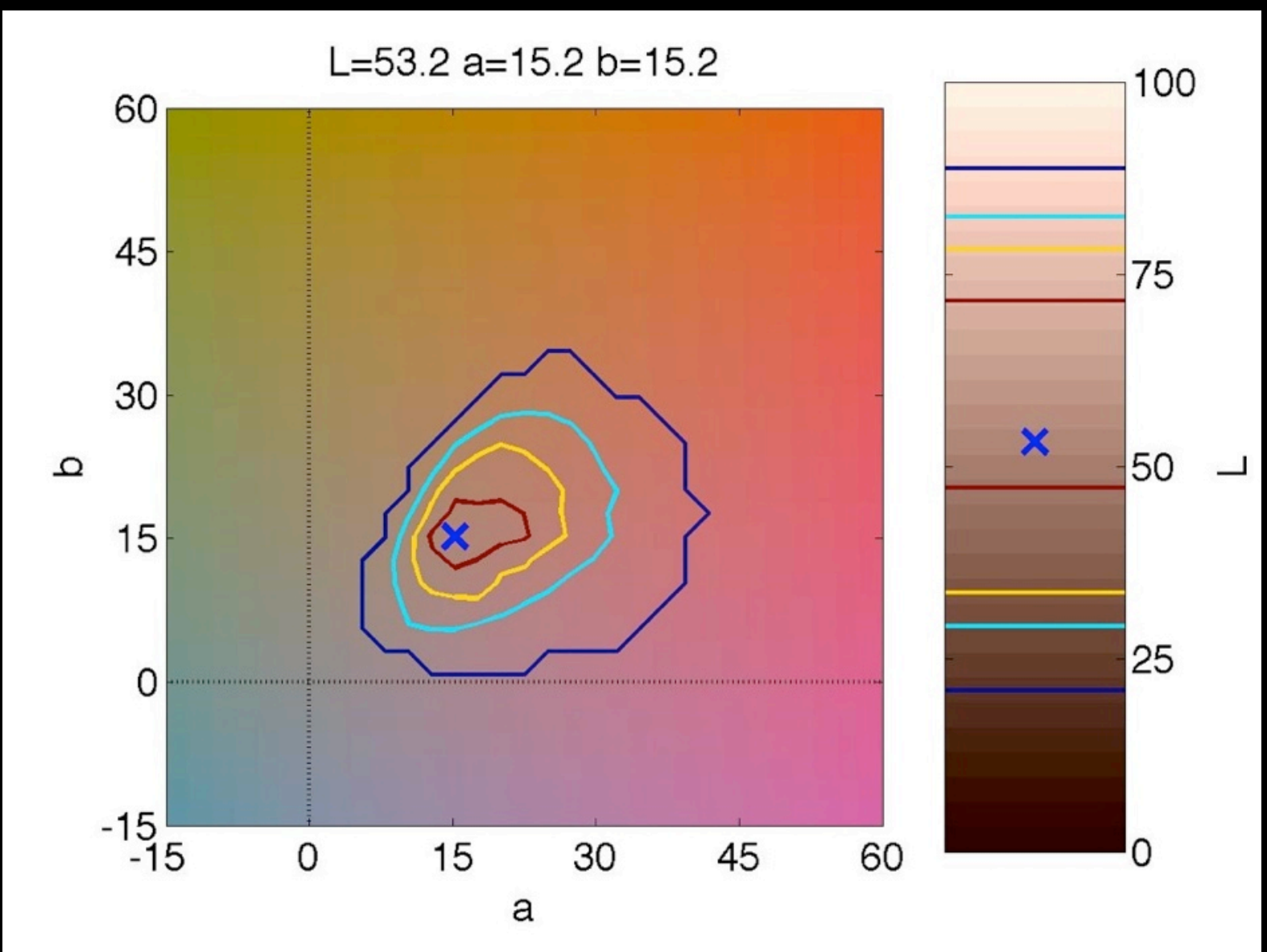

Nikon

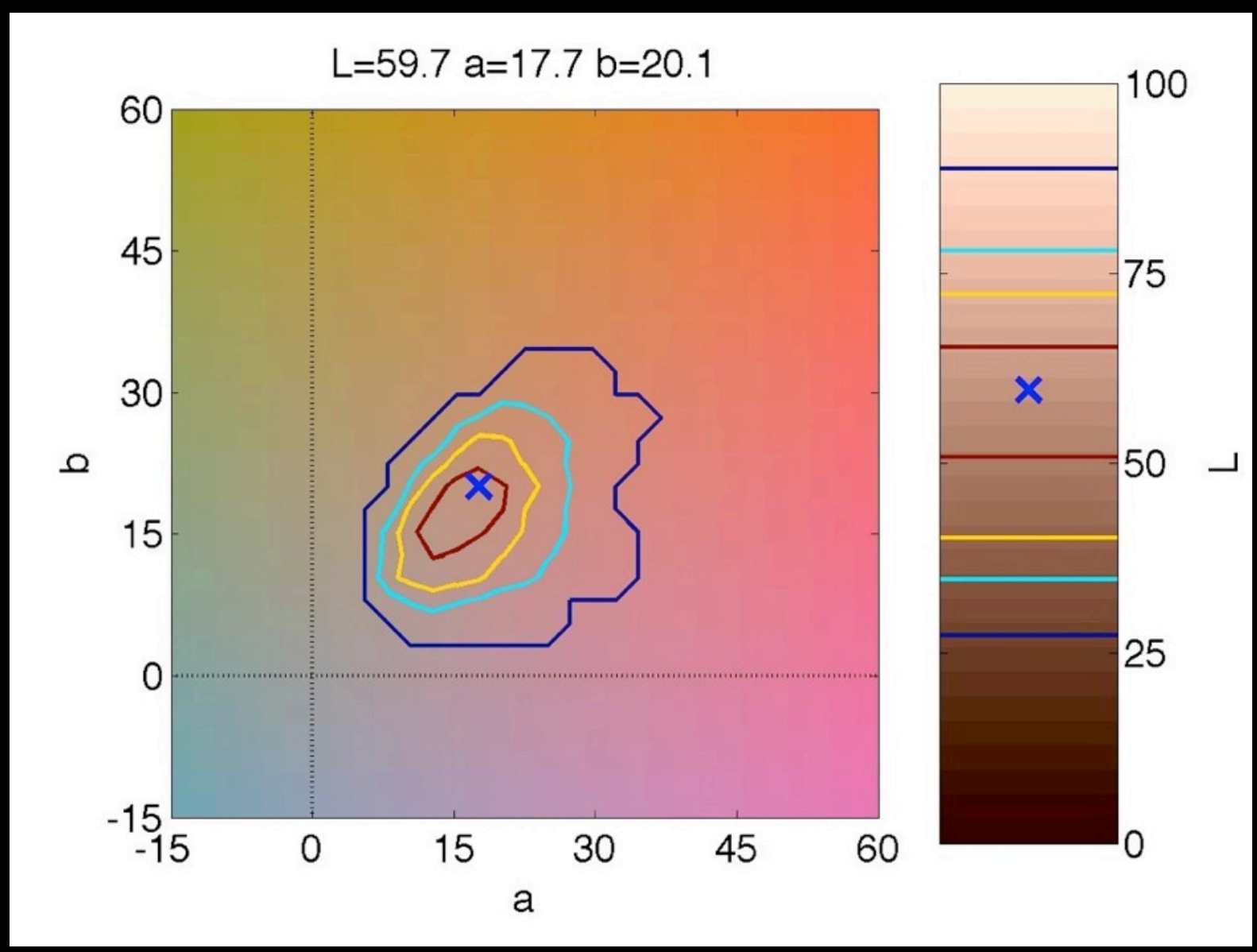

Nikon cameras constrain skin colors more than Canon cameras, especially along the $L$ axis. 


\section{Flash}

No flash

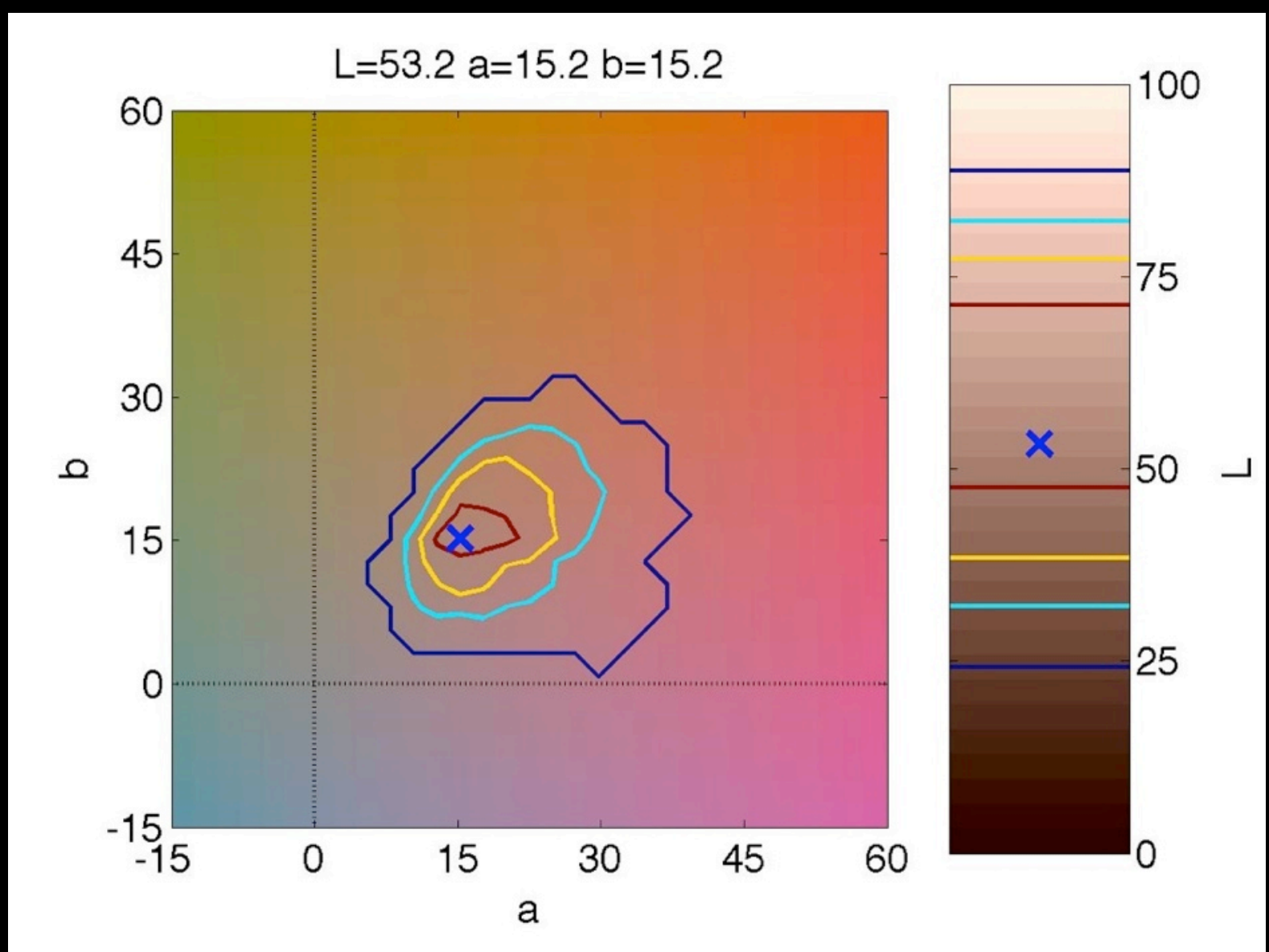

Flash

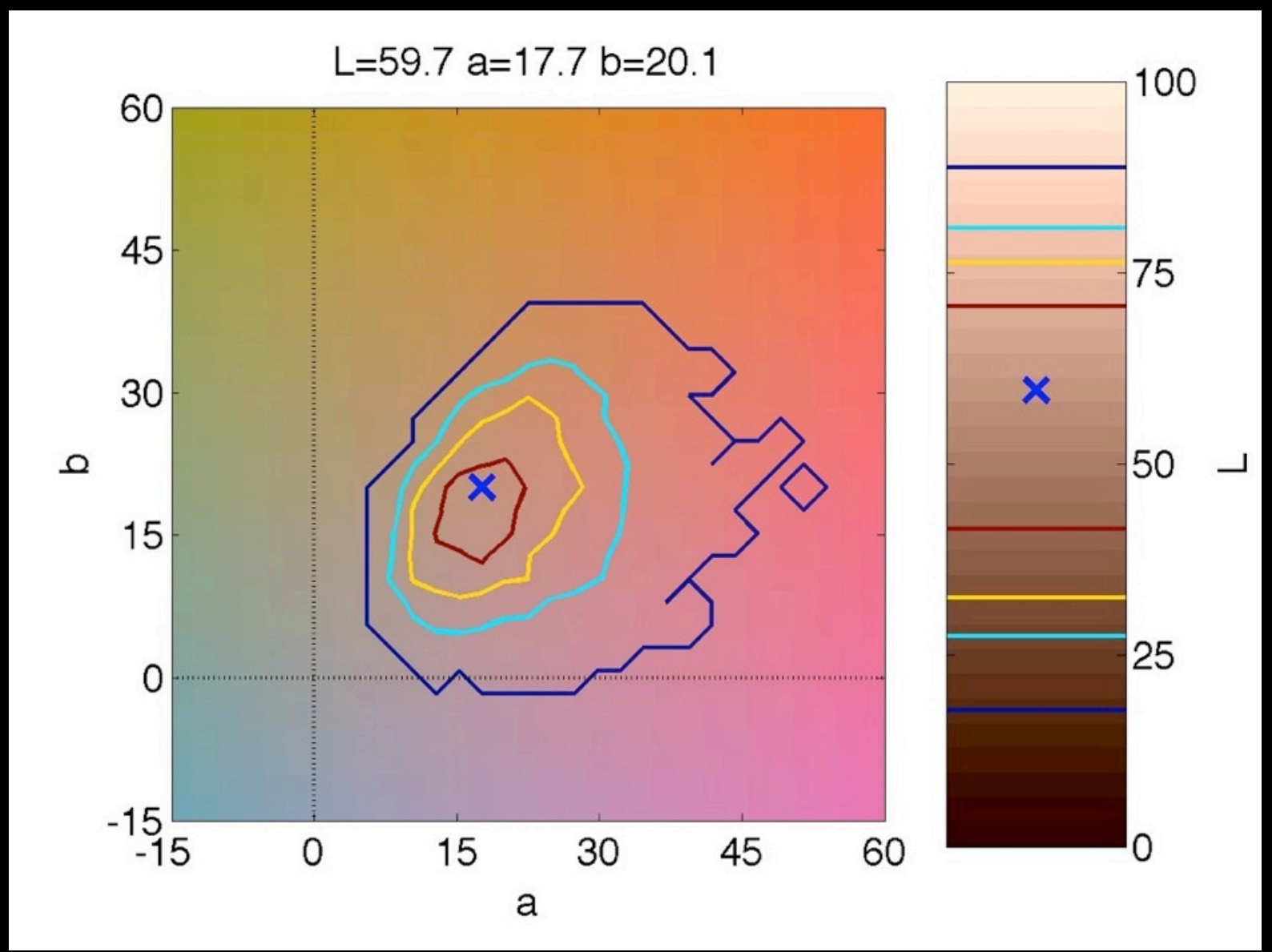

Flash adds more reddish skin tones. 


\section{$\Delta E$ and Significance}

Flash and cameratype

\section{Geolocation}
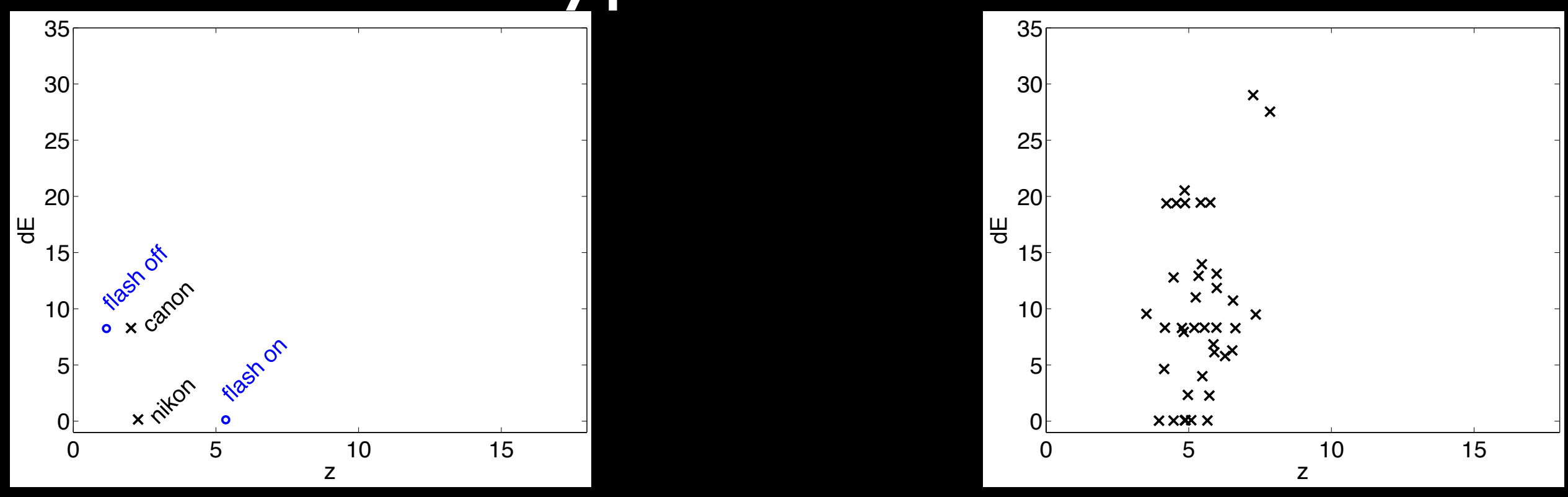

Keyword

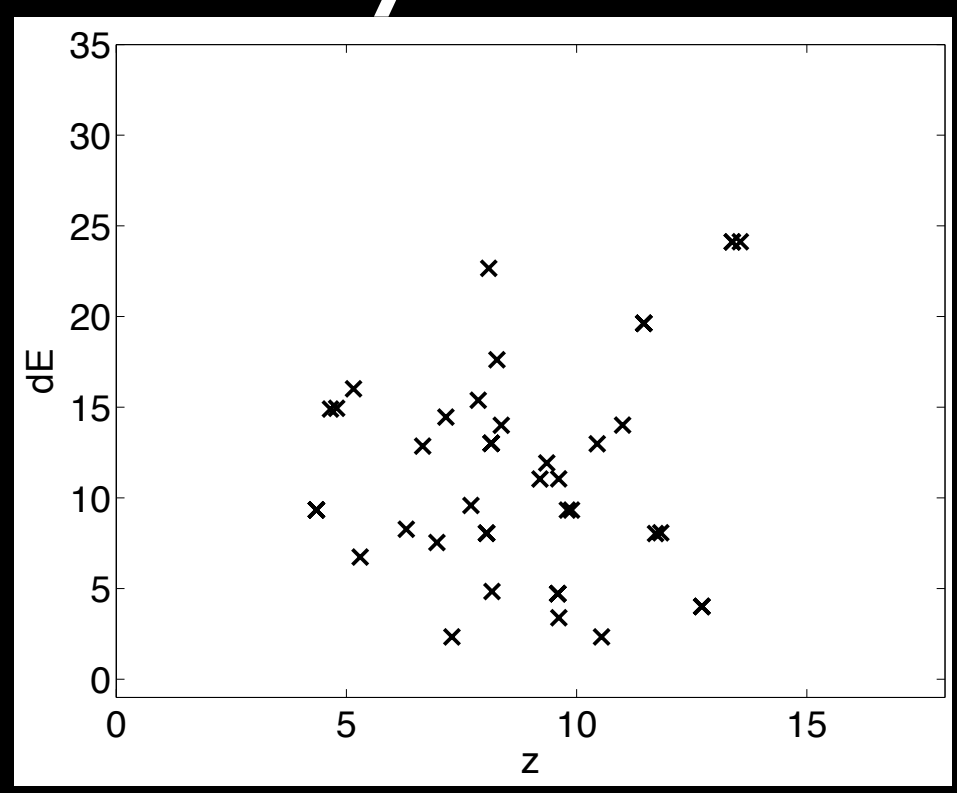

PubFig

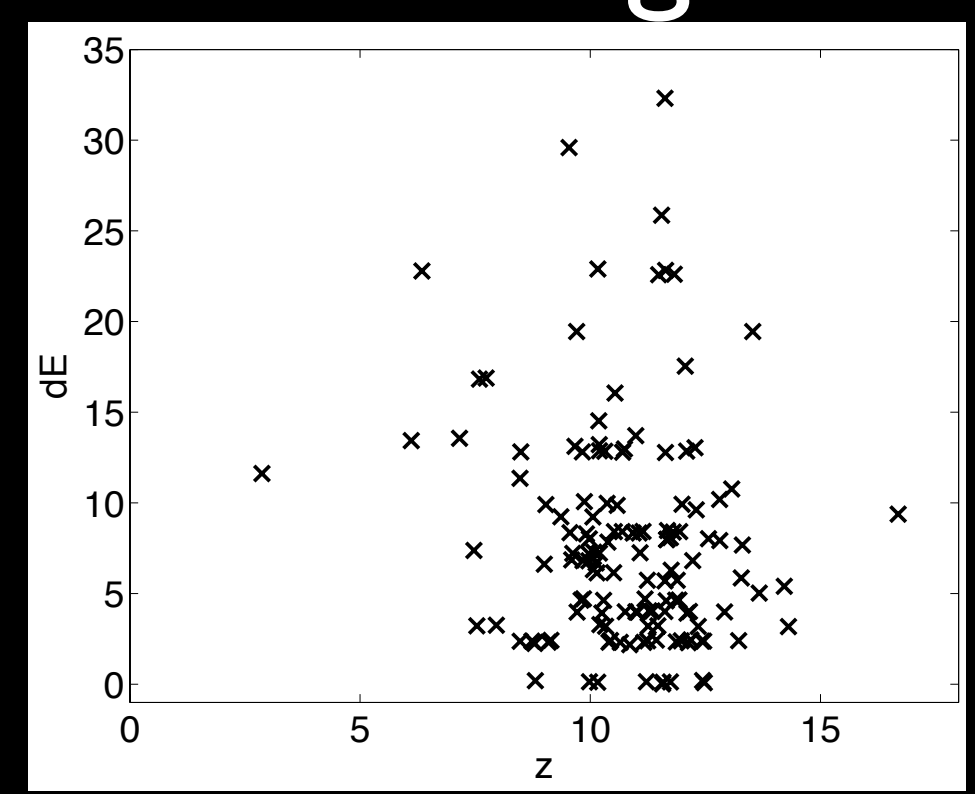




\section{$\Delta E$ and Significance}

Keyword

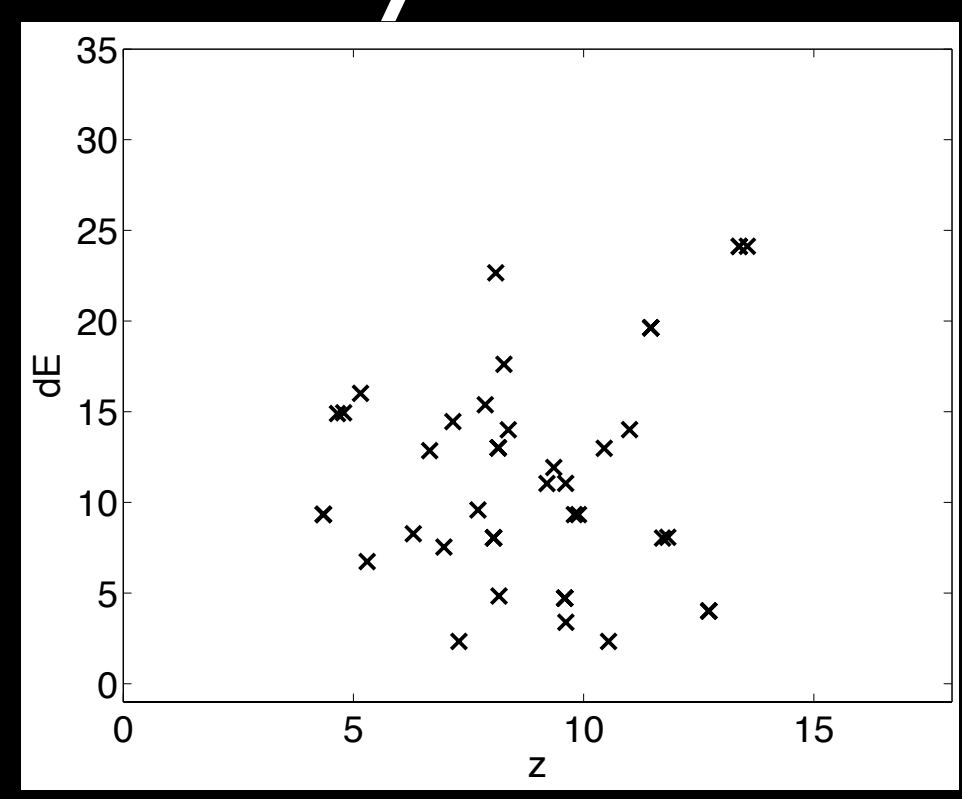

PubFig

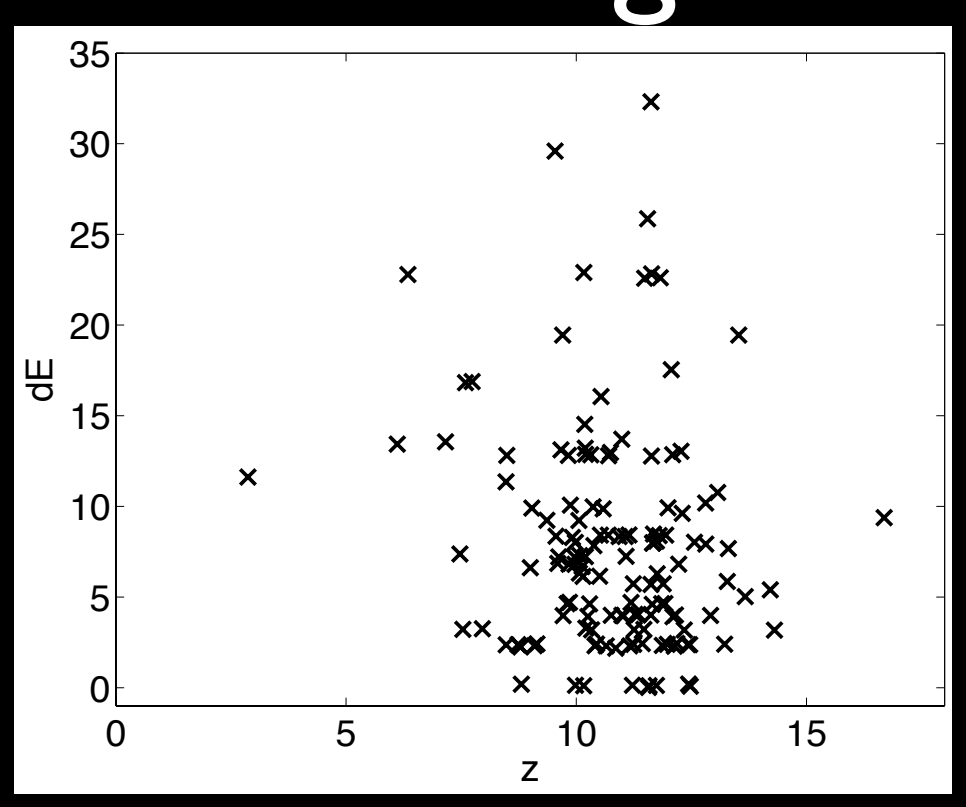

- Keywords and persons have strongest impact. 


\section{Skin Detection}




\section{Ground Truth}
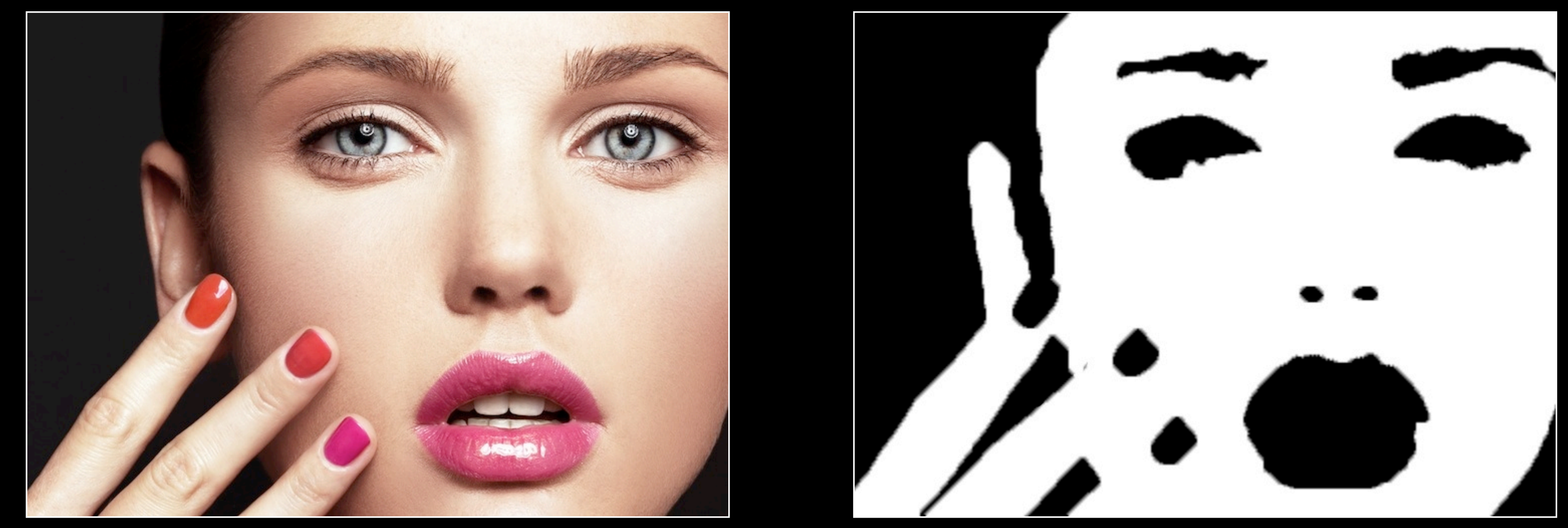

- Keywords: sunburn, paleness and beauty.

- 50 images each. 


\section{Skin Detection}

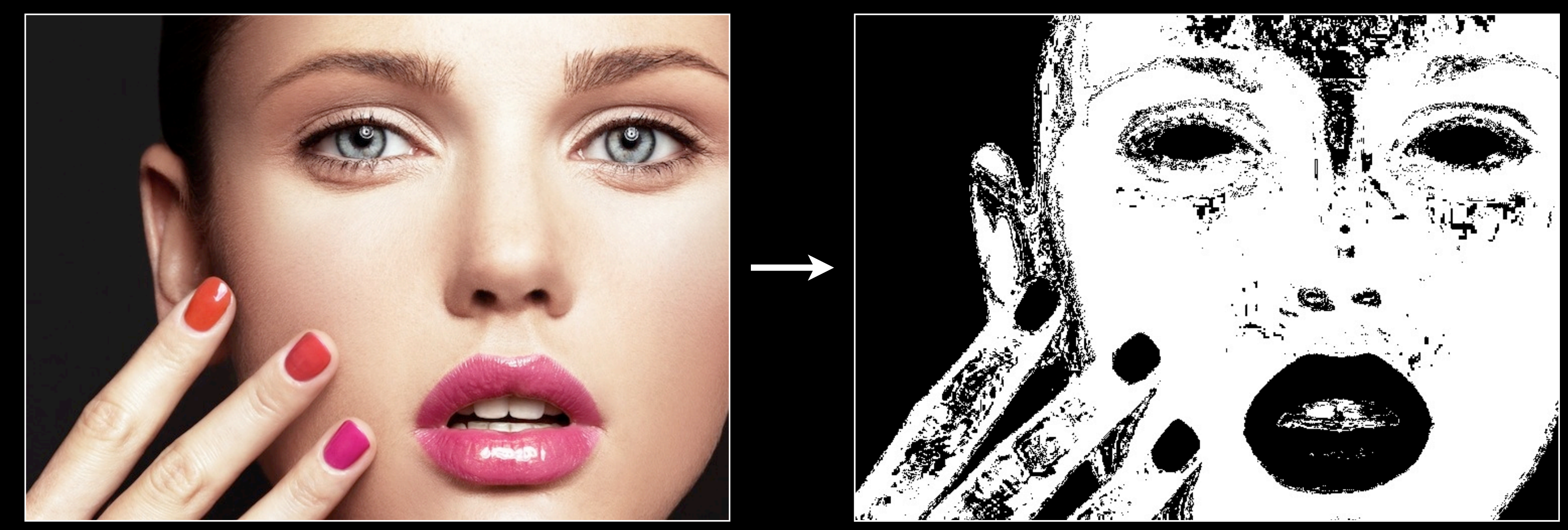

I. Significance map with z scores

2. Threshold T 


\section{Detection Results}

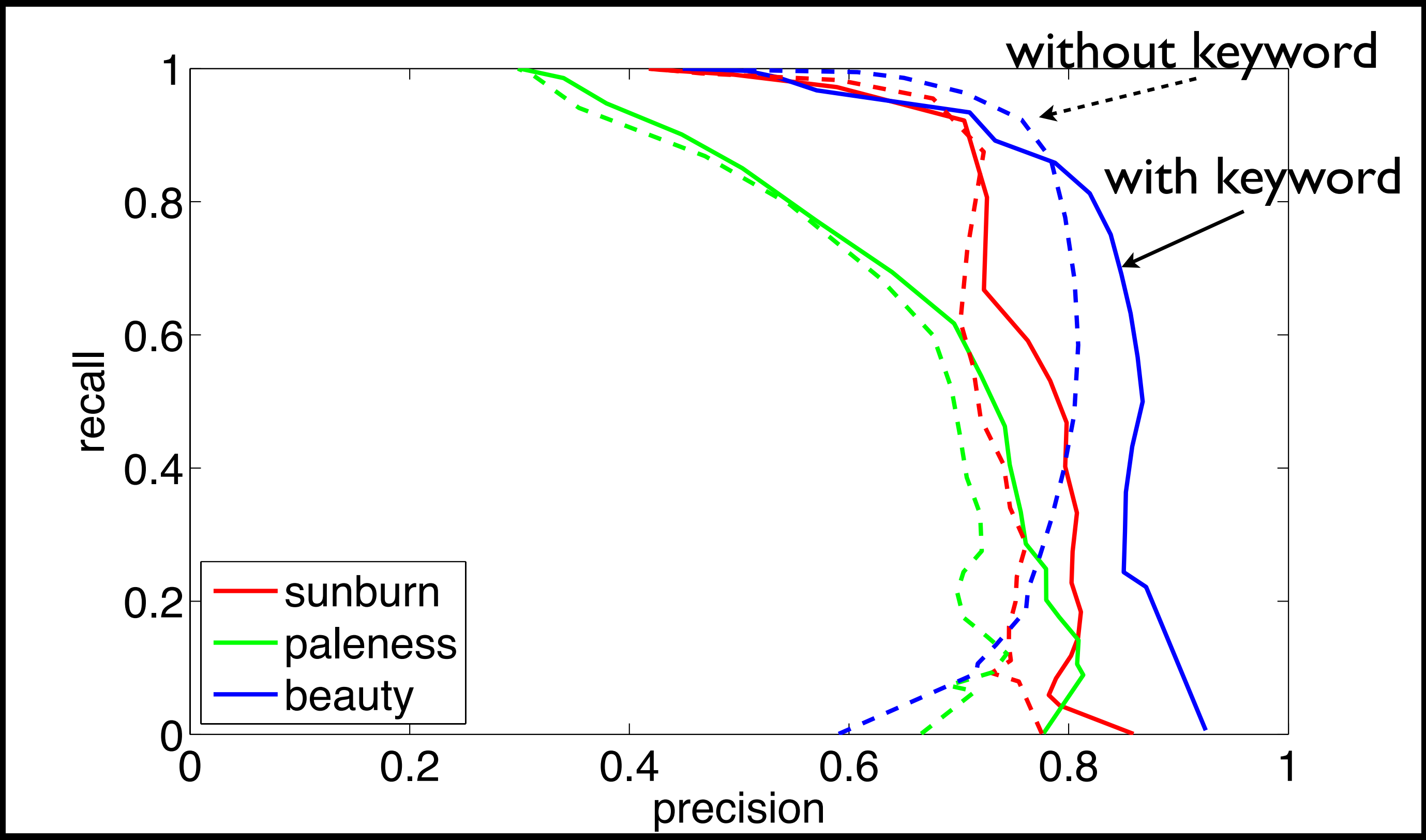

Keywords improve detection of skin regions. 


\section{Conclusions}

- Statistical framework to link image metadata with image characteristics.

- Impact of metadata on skin colors.

- Keyword enhanced skin detection.

- Take home message: Image-mining can save you from tedious work. 
Thank You 